\title{
PRACTICE
}

\section{Establishing a Statewide Celebration of Undergraduate Research: History and Lessons Learned}

Eric C. Freundt, University of Tampa

Kimberly R. Schneider, University of Central Florida

\begin{abstract}
The Florida Undergraduate Research Conference (FURC) is an annual multidisciplinary conference that enables student scholars to present their research, network with other students, and attend professional development seminars. FURC has been held since 2011 and has featured more than 2,100 student presentations with participation from a broad array of institutions within the state. Survey data indicate that FURC is the first conference presentation for the majority of participants and that participation in the conference is associated with several positive outcomes. This article describes the history, structure, and planning of the conference and as well provides survey and outcome data that may assist other states and geographic areas as they consider forming their own conferences.
\end{abstract}

Keywords: multidisciplinary regional conferences, networking, professional development, undergraduate research

doi: $10.18833 /$ spur/2/3/3

\section{Overview and History}

Conference participation by undergraduate researchers has a variety of benefits, including learning to communicate with a diverse audience, increasing self-confidence, problem solving, enhancing career readiness, and fostering collaborations (Hill and Walkington 2016; Kneale et al. 2016; Lopatto 2010; Mabrouk 2009). Although many institutions hold internal undergraduate research conferences, regional interdisciplinary conferences may provide a first opportunity for students to present their research to the broader academic community. Additionally, as indicated by the growth of such conferences, the relative ease and low cost of attending a regional or statewide undergraduate research conference enables broad participation (Swift et al. 2012; Wohlers et al. 2012).

In 2008, the University of Central Florida began hosting an annual statewide conference for undergraduate research professionals (Schneider, Harrison, and Aldarondo-Jeffries 2012). The conference, now in its 11th year, brings together faculty, administrators, and professional staff from across the state for networking and workshops on best practices in undergraduate research. One outcome of this conference was creation of the Florida Undergraduate Research Conference (FURC), which is an annual event open to all Florida undergraduate students for presentation of research in a poster format (see Table 1). The inaugural FURC was held at the University of North Florida in 2011, and the event has continued at a different institution each year for the past seven years (see Table 2). In addition to providing an opportunity to present research, FURC enables students to network with other student researchers and faculty, and to learn about opportunities for graduate education by speaking with representatives from graduate schools in Florida and across the United States. Additionally, the conference features a variety of professional development workshops for attendees. As is the case for other statewide undergraduate research conferences, FURC organizers seek to foster an environment of open and interdisciplinary dialogue and to encourage participation from a wide range of STEM and non-STEM disciplines (Swift et al. 2012; Wohlers et al. 2012). To foster discussion across academic disciplines, posters are not grouped according to subject area but interspersed. 
TABLE 1. Key Features of the Florida Undergraduate Research Conference (FURC)

- FURC is a statewide research conference that is open to all forms of undergraduate research and scholarship.

- The conference is held annually on the last weekend in February, with Florida host institutions changing from year to year.

- Registration fees have been kept low (\$50) to enable broad participation.

- All revenues are applied to the conference or passed to the next host institution for conference expenses. A small amount, \$5 per registration, is retained to fund a FURC student assistant.

- FURC opens on Friday evening with a reception. Saturday features student poster sessions and ends in the afternoon to allow travel.

- The conference includes an average of 10 different professional development sessions designed to benefit undergraduate researchers.

- The planning committee meets monthly throughout the year via conference calls and twice annually in-person at the conference and at the statewide symposium for undergraduate research professionals.

Note: See Schneider et al. 2012.

TABLE 2. Eight Years of FURC

\begin{tabular}{|l|c|c|c|c|c|}
\hline FURC Venues & Conf. year & Seminars & Institutions & Recruiters & Posters \\
\hline University of North Florida & 2011 & 8 & 17 & 4 & 135 \\
\hline Stetson University & 2012 & 9 & 23 & 7 & 171 \\
\hline University of Florida & 2013 & 13 & 23 & 13 & 292 \\
\hline Florida International University & 2014 & 6 & 27 & 32 & 280 \\
\hline $\begin{array}{l}\text { Embry-Riddle Aeronautical } \\
\text { University }\end{array}$ & 2015 & 8 & 21 & 22 & 228 \\
\hline University of Tampa & 2016 & 10 & 32 & 30 & 374 \\
\hline Florida Atlantic University & 2017 & 11 & 25 & 33 & 330 \\
\hline Eastern Florida State College & 2018 & 10 & 30 & 25 & 374 \\
\hline
\end{tabular}

Note: Host institutions (2011-2018) are shown, with the number of professional development seminars (Seminars), the number of participating institutions (Institutions), the number of graduate program representatives (Recruiters), and the number of student poster presentations (Posters).

Host institutions have included private universities as well as larger research universities (see Table 2). The most recent conference was the first time that FURC was held at a two-year college. The organizing committee is committed to having diverse institutions host the conference and has sought to plan the conference in different regions of the state in order to encourage participation from new institutions.

\section{Conference Schedule and Attendees}

A simple schedule was developed to allow travel on Friday and Saturday night. The conference begins with an opening reception on Friday evening that provides an opportunity for student networking. At several meetings, the reception also has featured a keynote speaker selected by the planning committee for the ability to connect scholarship with a variety of STEM and non-STEM disciplines. Saturday, the key day of the event, features the poster sessions and workshops, which are typically staggered to allow for three to four poster sessions and at least two sessions of concurrent workshops. Although it is a very full day, the schedule has been designed so that the event ends late afternoon on Saturday, allowing students to travel home after the conference and save money on an additional night of lodging.

Students and faculty have been surveyed regarding the schedule of events, and the results are presented in Figure 1. Generally, students and faculty have been satisfied with the overall length of the conference; almost 80 percent 
responded that the conference length was "just right," and 83 percent of respondents thought that the workshops were allowed the appropriate amount of time. Although FURC is not as long as many other academic conferences, very few survey respondents felt that the conference was too short (less than 5 percent of respondents in 2017 and 2018). Survey results also indicated that a one-hour poster session was optimal. The poster sessions were shortened to 45 minutes in 2018, which resulted in a sizable increase in the number of respondents indicating that the poster sessions were too short.

Attendees have included the presenters, faculty, and nonpresenting students. Over the past three years, roughly 10 percent of the attendees were students who were not presenting. Some academic programs are using this event to foster academic interest in their students, building excitement about engagement in research.

\section{Professional Development}

FURC represents the first academic conference for many attendees, and the organizing committee has sought to make the abstract review process a learning experience.
Student abstracts are reviewed by a faculty committee that is assembled and coordinated by the host institution. Faculty are encouraged to evaluate the quality of the writing and whether or not the abstract describes a scholarly project appropriate for that discipline. Those abstracts that do not meet the threshold of acceptance are returned with comments to the student and the faculty mentor, who likely did not review the student's abstract prior to submission. In these cases, the student is encouraged to revise and resubmit the abstract. This process allows students to learn how to compose a high-quality abstract and still have an opportunity to participate in the conference.

Many of the institutions that send students to FURC also have vibrant undergraduate research programs that include showcase events and professional development seminars for their students. However, not all institutions in the state provide these opportunities, and students who do have opportunities to attend professional development seminars may choose not to attend. Therefore, a key feature of the conference has been to provide workshops that benefit students with a wide range of experience, from first- and second-year students who may not yet be involved in

FIGURE 1. Conference Schedule Survey Results (Students and Faculty)

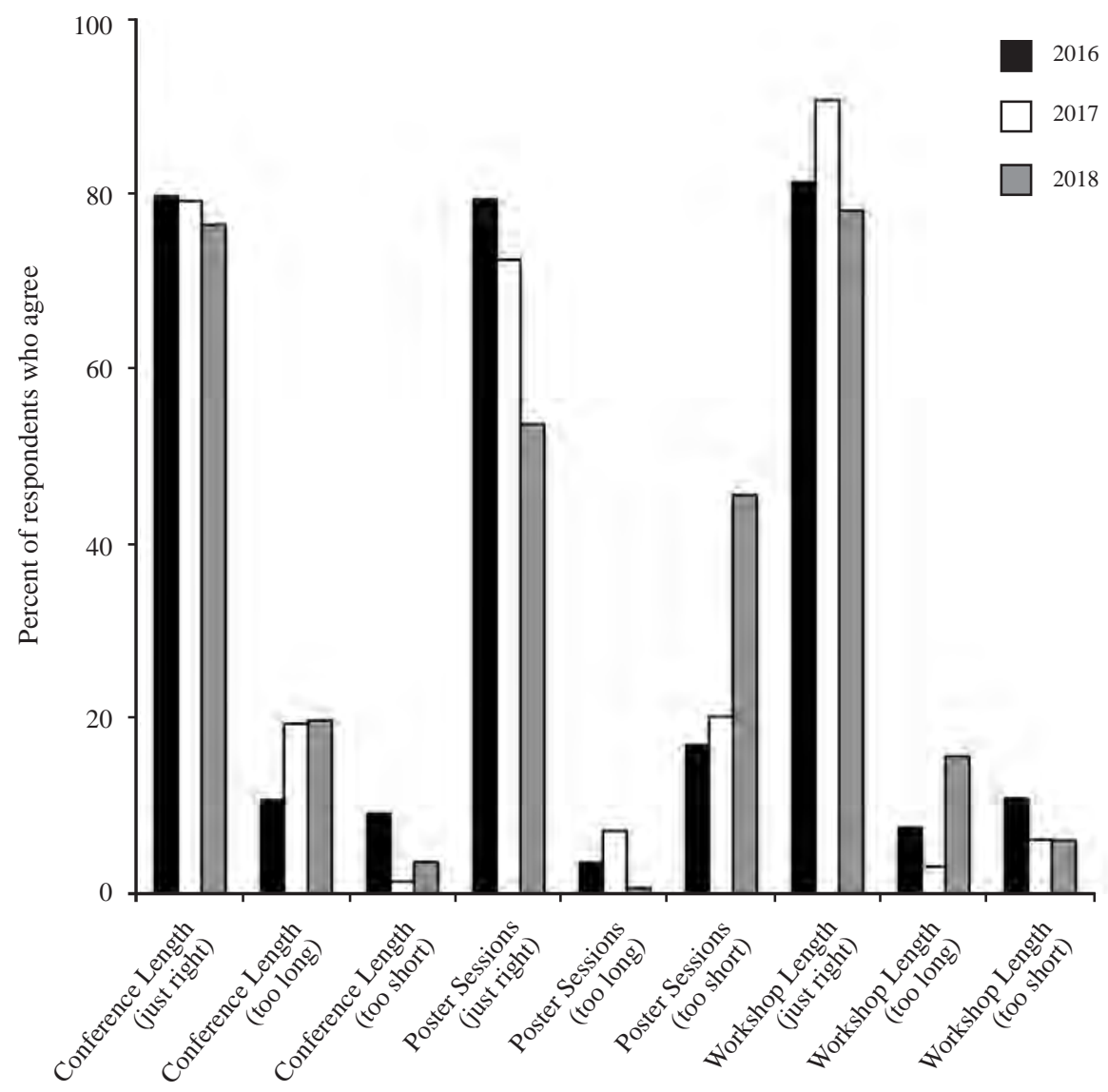

Note: $n=431$ (70 faculty and 361 students). 
research to fourth-year students who are preparing to enter the workforce or graduate/professional school. Examples of workshops that have been designed for early-stage undergraduate researchers and first- and second-year students include:

- "Getting Involved in Undergraduate Research as a Transfer Student"

- "Leadership in Undergraduate Research Programs"

- "Off-Campus Undergraduate Research Experiences"

- "How to Ask for, Process, and Use Feedback in Undergraduate Research"

Many of the most popular workshop offerings have been targeted to students who intend to pursue graduate education. Examples include:

- "Financing Graduate School"

- "How to Write an Effective Personal Statement"

- "Applying to Graduate and Professional School"

- "Preparing your Application for Research-Based Prestigious Awards and Fellowships"

- "Identifying a Good Adviser in Graduate School"

In addition, many workshops cover broadly applicable topics that are relevant to all levels of research experience, including:

- "Research Ethics"

- "Mentor-Protégé Relationships"

- "Finding One's Research Passion"

- "Best Practices for Preparing a Conference Presentation"

- "Developing an Online Academic Portfolio"

Student feedback on the workshops has been collected for the past three conferences and has been used to determine future workshop offerings. The workshops are generally positively reviewed, with many students expressing gratitude for the information provided. For example, quantifying the comments for the workshops in 2016 revealed that 70 percent of comments were considered positive, 20 percent negative, and 10 percent neutral. Several student comments regarding the workshops are presented below:

- "This workshop alleviated the stress that I felt before attempting to apply to Med School. I hope that having the right perspective will better my chances towards admission."

- "Very good presentation, was very informative about opportunities I did not know about beforehand."

- "Great summary of prestigious awards and had wonderful tips. Now I know where to start when applying."

- "It was insanely helpful and the presenter was way helpful and invited us to contact him in the future for anything. The handouts were very informative and I'm very glad I chose this workshop. I learned a lot and have examples and prompts to help me in the future."

- "Amazing workshop that allowed me to make many connections and learn about leadership."

\section{Planning and Organization}

Each year's planning committee has been composed of the conference founders as well as two members from the previous host institution, two members from the current host institution, and two members from the institution that will host the following year. Each member from a host institution thereby serves a three-year term. The structure of the committee allows for the current host to receive regular advice and feedback from the members who hosted the previous year and allows the future hosts to observe the planning process before it is their turn. This structure has allowed for effective knowledge transfer and communication of lessons learned, and has largely enabled a consistent format for the conference. Additionally, the committee has assembled a variety of documents to assist institutions planning to host the conference, including documents on best practices, college and university contacts, FAQs, and contacts for graduate school representatives.

The application to host FURC was developed using the application to host CUR events as a model, and it was written to ensure that potential hosts adequately consider the requirements and duties of organizing the conference. The applicants must provide a schedule of the conference in addition to deadlines for abstract submission and registration; a description of facilities that can be used for the conference events (including information on accessibility); plans for printing; directional signs; the review process for abstracts; acknowledgment of ability to assume responsibility for website and social media; plans for meals and reception; transportation options; hotel accommodations (including the number of available rooms and rates); a proposed budget; and a letter of support from the president or provost of the university. Although preparing the application requires a substantial amount of effort, it ensures that the host institution is fully aware of the hosting requirements and allows the planning committee to provide detailed feedback on potential issues before an institution is committed to hosting the conference.

\section{Budget}

Often the most difficult hurdle to overcome when gathering institutional support is ensuring that the conference will be able to cover its costs. Over the past eight years, the conference revenue has been sufficient to cover costs for all but one event, which had a negative balance due to overestimation of registrants and higher catering costs related to institutional restrictions. Approximately 60 percent of the budget goes toward food for the Friday-night reception and breakfast, lunch, and snacks on Saturday. Printing fees and supplies ( 20 percent) and facility rental fees ( $0-15$ percent) vary from institution to institution, with the remainder going toward student help (5 percent). Those institutions that have not had to pay for facilities have spent more on food and promotional items for students. 
FURC has been able to keep costs low for students (\$50) while providing a pleasant conference experience for participants by increasing the number of graduate recruiters and exhibitors at the conference, who pay $\$ 300$ for conference registration. The added benefit is that students learn about opportunities for graduate study and can continue to enhance their networking and communication skills. A rough budget is developed for the initial application to host the event. The planning committee reviews the budget and provides feedback based on previous events. The final budget is then submitted after the event and discussed with the committee.

\section{Outcomes and Survey Results}

FURC has seen participation grow considerably since its inception, from 135 presentations in 2011 to 374 in 2018 (a 239-percent increase), with 2,184 student research presentations given over that time period. On average, 25 institutions participated in the conference each year, representing four-year public, four-year nonprofit private, and two-year institutions (see Table 2).

Student participants (2016-2018) were surveyed about their experiences at the conference. The email survey was sent out following the conference. FURC represented the first conference presentation for the majority of participants (58 percent average) and, significantly, built confidence in research presentation (see Table 3). Conference attendees also expressed that participation enabled them to make connections with students at other universities, which has been noted elsewhere (Wohlers et al. 2012). They also found out about research opportunities at their home institutions, and by presenting at the conference, they learned more about their own research. Students also indicated that they received helpful feedback on their research at the conference. Moreover, the vast majority of attendees (90 percent) said they would recommend the conference to other students, indicating that the conference provided an overall positive educational experience (see Table 3). Over the past three years, the authors have observed that the vast majority of survey respondents (students and faculty) learned about the conference from a faculty member (43 percent) or staff in the campus undergraduate research office (42 percent; see Figure 2). These results indicated that faculty and undergraduate research program directors were key outreach constituents in the planning of a regional or statewide conference.

\section{Future Challenges and Plans}

Many of the challenges faced by other statewide and regional conferences, including the Southern California Conferences for Undergraduate Research (SCCUR) and others described in CUR Quarterly, also have been encountered in planning FURC (Swift et al. 2012). Many of the lessons learned have been summarized in Table 4 . With the adoption of a model of moving the conference to a new institution each year, there is the added challenge of gaining support from new administrators every year. In addition, the FURC website has been designed and maintained by the host institution each year, and host institutions have been responsible for creating the online mechanisms for abstract submission, abstract review, and conference registration. The organizing committee has discussed the inefficiency of requiring each institution to reinvent these processes. In the future, the hope is to streamline this process by developing a single website maintained by the planning committee.

As was done by the SCCUR organizers, the FURC planning committee has begun the process of becoming a

TABLE 3. Survey of FURC Student Participants

\begin{tabular}{|l|c|c|}
\hline Survey item & Percentage \pm SD & Score \\
\hline $\begin{array}{l}\text { I learned about new research opportunities at my institution } \\
\text { by looking at the other posters. }\end{array}$ & $53 \% \pm 11.6$ & 3.6 \\
\hline I made connections with students at other institutions. & $79 \% \pm 5.5$ & 4.0 \\
\hline I received helpful feedback on my research project. & $56 \% \pm 2.6$ & 3.6 \\
\hline $\begin{array}{l}\text { I feel more confident about presenting a poster after } \\
\text { participating in FURC. }\end{array}$ & $92 \% \pm 3.5$ \\
\hline $\begin{array}{l}\text { Participating in FURC allowed me to learn more about my } \\
\text { research topic. }\end{array}$ & $62 \% \pm 3.1$ & 3.7 \\
\hline $\begin{array}{l}\text { The conference was well attended. } \\
\text { I would recommend FURC to other students. }\end{array}$ & $92 \% \pm 3.0$ & 4.4 \\
\hline
\end{tabular}

Note: Percentage indicates the percent of respondents choosing "Agree" or "Strongly Agree" \pm standard deviation. Score indicates the mean Likert score from 1 to 5. Data are from the 2016, 2017, and 2018 conferences $(n=332$ student respondents). 


\section{FIGURE 2. How Conference Participants Learned about FURC}

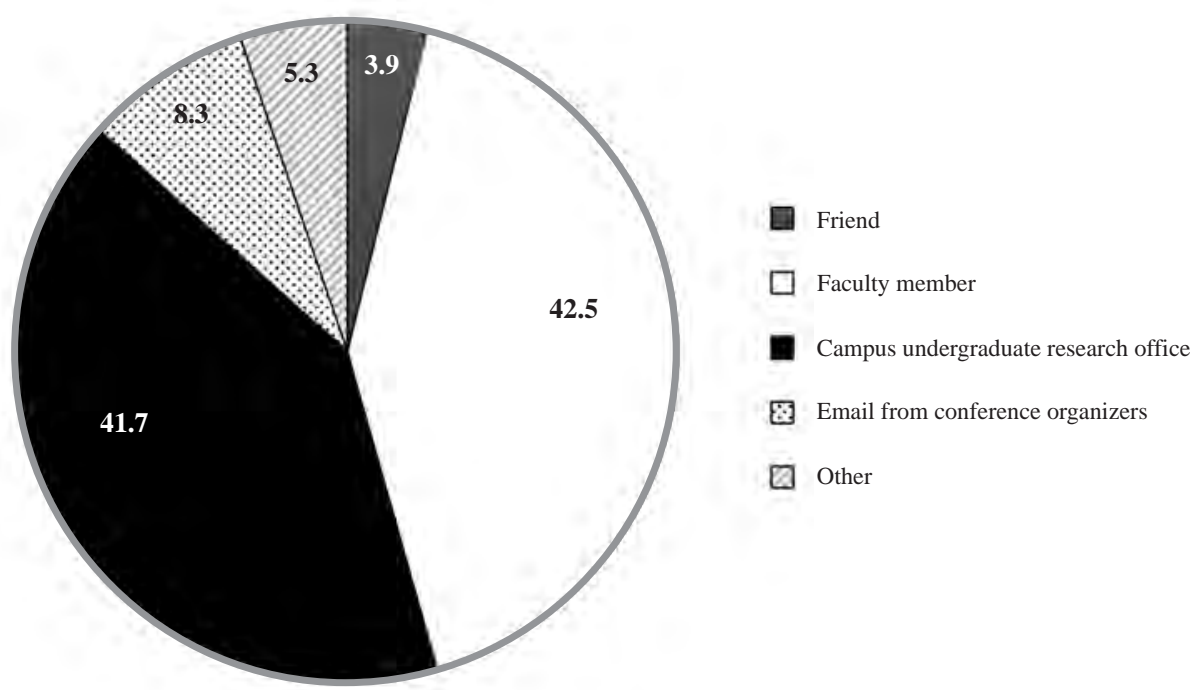

Note: Values indicate the average percentage from 2016-2018; $n=429$ (62 faculty and 367 students).

TABLE 4. Eight Years of FURC: Lessons Learned

- Ensure a range of professional development topics that are relevant to first- and second-year students with no research experience to those preparing to graduate.

- Include as many graduate schools as possible. The students are excited to learn about opportunities, and fees charged to the exhibitors help keep conference fees low for students.

- Focus on non-STEM workshop offerings to increase participation of non-STEM student scholars.

- The poster sessions should be a minimum of one hour, and transition times should be built into the schedule.

- Create a place for students to leave their posters, like a coat check, but make sure it is well staffed to accommodate the rush of students before and after poster sessions.

- Lines can disrupt the schedule. Ensure adequate flow at meals, etc.

nonprofit corporation. It is envisioned that nonprofit status will formalize the planning and procedures for hosting the conference and enable the FURC planning committee to work more effectively with host institutions.

The coming year will be the first time that an institution has hosted FURC twice; the University of North Florida served as the inaugural site and will again host the meeting in 2019. Florida Gulf Coast University has been selected as the host for 2020. FURC looks forward to continued growth and improvement in the future.

\section{Acknowledgments}

The success of FURC and this report would not have been possible without the dedication and support of the FURC planning committee members, especially LouAnne
Hawkins, Anne Donnelly, Eric Werner, Aaron Clevenger, Catherine Wrobel, Caroline Day, Jennie Soberon, Donna Chamely-Wiik, Ashley Spring, and Scott Herber. The authors also acknowledge the many workshop presenters who have contributed their time and energy to the conference.

\section{References}

Hill, Jennifer, and Helen Walkington. 2016. "Developing Graduate Attributes through Participation in Undergraduate Research Conferences." Journal of Geography in Higher Education 40: 222-237. doi: 10.1080/03098265.2016.1140128

Kneale, Pauline, Andrew Edwards-Jones, Helen Walkington, and Jennifer Hill. 2016. "Evaluating Undergraduate Research Conferences as Vehicles for Novice Researcher Development." International Journal for Researcher Development 7:159-177. doi: 10.1108/ijrd-10-2015-0026 
Lopatto, David. 2010. Science in Solution: The Impact of Undergraduate Research on Student Learning. Tucson, AZ: Research Corporation for Science Advancement.

Mabrouk, Patricia A. 2009. "Survey Study Investigating the Significance of Conference Participation to Undergraduate Research Students." Journal of Chemical Education 86:1335-1340. doi: 10.1021/ed086p1335

Schneider, Kimberly R., Richard Harrison, and Michael Aldarondo-Jeffries. 2012. "Engaging Undergraduate Research Professionals: A Statewide Symposium." CUR Quarterly 32(4): 37-38.

Swift, John N., Elizabeth L. Ambos, Cheryl Swift, and Carolyn Ash. 2012. "A Regional Undergraduate Research Conference Comes of Age in Southern California." CUR Quarterly 32(4): 21-27.

Wohlers, Tony E., Gregory M. Wilson, Narasinga Rao, Lori Gwyn, Kathryn Schoonover-Redden, and Jerry R. Malayer. 2012. "Celebrating Undergraduate Research in Oklahoma: The History and Impact of Statewide Undergraduate Research Conferences." CUR Quarterly 32(4): 15-20.
Eric C. Freundt

University of Tampa, efreundt@ut.edu

Eric C. Freundt is the director of the Office of Undergraduate Research and Inquiry and associate professor of biology. He has been a member of the Florida Undergraduate Research Conference planning committee since 2012 and served as a host coordinator in 2016. He received a BS in biology from Middle Tennessee State University and a DPhil in clinical medicine from Oxford University. His research interests are in virology, microbiology, and cell biology, and he regularly mentors undergraduate students in his lab.

Kimberly R. Schneider is the founding director of the Office of Undergraduate Research and assistant dean in the Division of Teaching and Learning at the University of Central Florida. She has a BS from the University of Florida in zoology and PhD from the University of South Carolina in biological sciences. Her research interests include marine ecology, science education, and highimpact learning practices.

\section{Upcoming CUR Events}

April 29-30, 2019:

Posters on the Hill, Washington, DC

May 23-25, 2019:

Second World Congress on Undergraduate Research, University of Oldenburg, Oldenburg, Germany

June 25-29, 2019:

CUR Annual Business Meeting and Undergraduate Research Programs Conference, The Ohio State University, Columbus, $0 \mathrm{H}$

July 11-15, 2019:

CUR Proposal Writing Institute, Kentucky Wesleyan College, Owensboro, KY

Visit https://www.cur.org/what/events/ 